Bull. Mater. Sci., Vol. 8, No. 4, October 1986, pp. 541-542.

(C) Printed in India.

\title{
Thermoluminescence of alkali halides doped with alkaline earth impurities
}

\author{
A R LAKSHMANAN and S V MOHARIL* \\ Division of Radiological Protection, Bhabha Atomic Research Centre, Bombay 400085 , \\ India \\ *Department of Physics, Nagpur University, Nagpur 400 010, India \\ MS received 31 March 1986; revised 12 May 1986
}

In this note we elaborate some points on LiF mentioned in the review article on "Thermoluminescence of alkali halides doped with alkaline earth impurities" by Deshmukh and Moharil (1985), hereafter referred to as paper I.

(1) The last sentence in $\S 3.1$ of paper I states "In recent years, the $285^{\circ} \mathrm{C}$ peak has been correlated with the $310 \mathrm{~nm}$ band (Lakshmanan et al 1982)". This should read as "In recent years, the $285^{\circ} \mathrm{C}$ peak (peak No. 7 according to the notation of Sunta et al 1971) has been correlated by Lakshmanan et al (1982) with two-electron centres". Lakshmanan et al's (1982) studies have shown that there is a trap conversion between peak 7 and $450^{\circ} \mathrm{C}$ (peak 10) centres just as one would expect from $Z_{2} \rightleftarrows Z_{3}$ trap conversion. This has prompted them to suggest that peak 7 correlates with $Z_{2}$ centres; not to be confused with $310 \mathrm{~nm}$ band as assigned by Nink and Kos (1976). Peak 7 optical absorption (OA) is not yet identified unambiguously because of the presence of intense $F(250 \mathrm{~nm})$ band.

Mayhugh (1970) established that the $200^{\circ} \mathrm{C}$ TL peak (peak No. 5) corresponds to the $310 \mathrm{~nm}$ OA band. It is now generally agreed that Nink and Kos's (1976) identification of $310 \mathrm{~nm}$ OA with $Z_{2}$ centres in LiF:Mg, Ti is not correct (Jain and Kathuria 1978; Nepomnyashchikh and Radzhabov 1980; Horowitz 1982; Caldas $e t$ al 1983; Mckeever 1984; Lakshmanan 1984).

(2) Mort (1966) and Mort and Zimmerman (1966) empirically predicted the $Z_{3}$ centre absorption maximum at $225 \mathrm{~nm}$ in $\mathrm{LiF}: \mathrm{Mg}$. Nepomnyashchikh and Radzhabov (1980) again predicted the absorption of $\mathrm{Mg}^{\circ}$ type centres from semiempirical relation at $225 \mathrm{~nm}$. Lopez and Lopez (1981) predict that $\mathrm{Mg}$ should act as an electron trap. On the contrary, Bosi and Nimis (1985) in a recent analysis predict that $\mathrm{Mg}$ should form $Z$ centres in LiF. All these diverse predictions show that such an analysis is premature.

(3) The arguments concerning $310 \mathrm{~nm} \rightarrow 225 \mathrm{~nm}$ conversion during low temperature optical bleaching and the correlation of $310 \mathrm{~nm}$ and $225 \mathrm{~nm}$ OA bands with $\mathrm{Mg}^{+}$ and $\mathrm{Mg}^{0}$ centres by Nepomnyashchikh and Radzhabov (1980) (refer $\S 4 \cdot 1$ ) have been questioned recently by Lakshmanan et al (1985). If the argument that all $\mathrm{Mg}^{+}$ centres change to $\mathrm{Mg}^{0}$ centres when peak 5 readout is correct, then one should not have observed peak 5 at all. Even if one assumes that only some $\mathrm{Mg}^{+}$centres change to $\mathrm{Mg}^{\circ}$ centres, then the peak 10 (correlated with $225 \mathrm{~nm} \mathrm{OA}$ ) $\mathrm{TL}$ in virgin $\mathrm{LiF}$ TLD-100 should have been considerably greater than that for the $140^{\circ} \mathrm{C}$ preirradiation annealed sample, because peak 5 (correlated with $310 \mathrm{~nm}$ OA) TL traps 
and hence the electrons released from them are a factor of 20 to 30 times higher in the former sample than in the latter one. But experiments show no appreciable difference in peak $10 \mathrm{TL}$ between the two samples (Lakshmanan et al 1985).

(4) In $\$ 4 \cdot 1$ of paper I, it is also mentioned that ESR measurements by Watterich et al (1980) show that in LiF: $\mathrm{Mg}$, the $g$ value is 2.006 for the $F$ band and 2.029 for the $225 \mathrm{~nm}$ band suggesting that the latter is not a $Z_{3}$ band. Nevertheless, this band seems to be definitely related to the presence of $\mathrm{Mg}$. Subsequently Watterich $e t$ al (1984) stated that the presence of $\mathrm{OH}$ in $\mathrm{LiF}: \mathrm{Mg}$ made the ESR investigation of any $\mathrm{Mg}^{+}$ions impossible upto now.

Landreth and Mckeever (1985) have recently reported that from their optical absorption data on $\mathrm{LiF}: \mathrm{Mg}$, Ti, they find no compelling evidence to relate either the $4.4 \mathrm{eV}$ or the $5.3 \mathrm{eV}$ bands to Z-type centres. The $5.7 \mathrm{eV}$ may be a Z-type defect but of unknown structure. Hence more detailed experimental studies including optical absorption, ESR, ENDOR, Faraday rotation etc are needed to identify the TL trap centres bearing in mind that the behaviour of $\mathrm{LiF}$ could be different from other alkali halides.

As mentioned in paper I, the ultimate photon emission step is not satisfactorily elaborated in any of the models in literature. The mobile electron and mobile interstitial models have led to two groups of researchers, each proceeding almost independently and ignoring the work of the other. The recent article by Lakshmanan et al (1985) attempts to answer these questions in LiF TLD-100 and suggests that both the processes may be operating at the same time.

\section{References}

Bosi L and Nimis M 1985 Phys. Status Solidi B131 K111

Caldas L V E, Mayhugh M R and Stoebe T G 1983 J. Appl. Phys. 543431

Deshmukh B T and Moharil S V 1985 Bull. Mater. Sci. 7427

Horowitz Y S 1982 Phys. Status Solidi A69 K29

Jain V K and Kathuria S P 1978 Phys. Status Solidi A50 329

Lakshmanan A R, Chandra B and Bhatt R C 1982 J. Phys. D14 1683

Lakshmanan A R 1984 Radiat. Prot. Dosim. 652

Lakshmanan A R, Bhuwan Chandra, Bhatt R C, Hoffmann W and Spallek R 1985 J. Phys. D18 1673

Landreth J L and Mckeever S W S 1985 J. Phys. D18 1919

Lopez F and Lopez F A 1981 Cryst. Lattice Defects 9131

Mckeever S W S 1984 Radiat. Prot. Dosim. 83

Mayhugh M R 1970 J. Appl. Phys. 414776

Mort J and Zimmerman D W 1966 Phys. Lett. 21273

Mort J 1966 Phys. Lett. 21124

Nepomnyashchikh and Radzhabov E A 1980 Opt. Spectrosc. (USSR) 48154

Nink R and Kos H J 1976 Phys. Status Solidi A35 121

Sunta C M, Bapat V N and Kathuria S P 1971 Proc. Third Int. Conf. on Lum. Dosimetry, Riso Report No. 249, Danish AEC and IAEA p 146

Watterich A, Foldvari I, Corradi G and Opyrchal H 1984 Phys. Status Solidi B121 117

Watterich A, Foldvari I and Voszka R $1980 \mathrm{~J}$. Phys. (Paris) 41 C6-159 